\title{
O alçamento de vogais médias pretônicas e os itens lexicais
}

\author{
Maria do Carmo Viegas \\ UNIVERSIDADE FEDERAL DE MINAS GERAIS
}

\section{Abstract}

The main purpose of this paper is to make evident that many lexical items of the portuguese language cannot be seen as exceptions to the pretonic mid vowels raining rules as they have been considered and that through the residue analysis the remaining exceptions bring out the need of understanding language as "enunciacalo" in the linguistic change processes. 
0. Este texto procura repensar alguns trabalhos feitos até então a respeito do alçamento de vogais médias pretônicas no português em busca de caminhos para um melhor equacionamento do problema. Na primeira parte faço uma revisão comentada da literatura mais recente a respeito do alçamento; na segunda, faço uma pesquisa histórica de itens sempre alçados na região de Belo Horizonte e argumento que estes itens sempre tiveram vogal alta em sua pronúncia, apesar dos e's e o's da sua grafia, não podendo ser considerados para o estabelecimento de regras ou processos de alçamento; na terceira parte, com base nas evidências encontradas, concluo optando por considerar as mudanças lingüísticas como processos inerentes a uma concepção de léxico e de língua que considere o momento da enunciação e o sistema da língua como relacionados e interativos.

1. O alçamento de vogais médias pretônicas (pirigo, cunversa), ou elevação do traço de altura das vogais médias, é um processo antigo no português e já era mencionado em OLIVEIRA, F. de (1975 [1536]:64).

Das vogais, entre u e o pequeno há tanta vizinhança, que quase nos confundimos, dizendo uns somir e outros sumir $e$ dormir ou durmir e bolir ou bulir e outras tantas partes semelhantes (...)

No Brasil, o alçamento muitas vezes caracteriza diferenças dialetais. Para citar somente a bibliografia mais recente, temos em BISOL (1981) um detalhado trabalho a respeito desta elevação no dialeto gaúcho, em que é feita uma análise quantitativa e qualitativa da variação [e] [i] e [o] [u], descrita através de regras variáveis de 
Rev. Est. Ling., Belo Horizonte, ano 4, v. 2, p. 101-123, jul./dez. 1995

harmonização vocálica. ${ }^{1}$

Em ABAURRE-GNERRE (1981) temos um estudo dos "Processos fonológicos segmentais como índices de padrões prosódicos diversos nos estilos formal e casual do Português do Brasil", em que inclui-se a elevação do traço de altura das vogais médias pretônicas do dialeto capixaba. Argumenta Abaurre-Gnerre a favor de a elevação da vogal não ser um processo de harmonia vocálica e, sim, um processo de redução. Propõe a autora "a existência de uma relação entre harmonia vocálica e ritmos predominantemente silábicós e entre levantamento (e eventual queda) de vogais e ritmos predominantemente acentuais".

PASSOS, PASSOS \& ARAÚJO (1980) é um estudo a respeito da relação entre levantamento de vogal média pretônica, estilo e estrutura da sílaba, no dialeto falado por moradoras de Salvador (BA). ${ }^{2}$

Em VIEGAS (1987), acerca do dialeto falado na região de Belo Horizonte, menciona-se a questão do alçamento como sendo possivelmente um processo de difusão lexical. No trabalho de Viegas postula-se a existência de regras ${ }^{3}$, mas:

...a descrição do fenômeno através de uma regra variável lexicalmente abrupta, como apregoavam os neo-gramáticos, não dá conta da complexidade do processo de alçamento das vogais médias pretônicas, ou seja, a regra variável da gramática ao atuar no léxico sofre restrições deste, restrições não previstas nesta teoria. Os trabalhos a respeito do alçamento até então se basearam em regras categóricas ou em regras variáveis lexicalmente abruptas. Os estudos a respeito da difusão lexical me orientaram no sentido de o alçamento se processar gradualmente através do léxico. PHILLIPS (1984) me fornece subsidios para afirmar que a regra de alçamento atua sobre os itens mais freqüentes primeiro. Ao tentarmos precisar a medida desta freqüência, além da dificuldade em fazê-lo, temos que considerar e relevar a influência dos fatores não estruturais em relação ao léxico e seu uso. Além disso, alguns itens escaparam a qual- 
quer sistematização, o que me fez observar a importância de cada item ter sua própria história. A força do componente semântico, até então não considerada nas mudanças sonoras, foi neste trabalho evidenciada. Assim, os individuos repassam e reforçam os valores dos conteúdos semânticos dos itens, que estão relacionados com os valores sociais, para a forma fonética destes itens, que também está associada a valores sociais. (VIEGAS, 1987:168)

Deste trabalho ficaram algumas questóes que precisam ser melhor esclarecidas. Que itens foram afetados pelas mudanças primeiro? Por que estes e não outros? Como se fez/faz a implementação da mudança através do léxico? Como deve ser medida a freqüência do item, já que este parece ser um fator favorecedor à mudança do item?

Existem dois modelos bem distintos acerca da teoria da mudança lingüística. Segundo os neogramáticos, a mudança sonora é foneticamente gradual e lexicalmente abrupta. Já de acordo com os difusionistas (WANG e outros) a mudança sonora é foneticamente abrupta e lexicalmente gradual.

A questão de como a mudança se processa foneticamente tem sido bastante discutida dentro do modelo da Difusão Lexical e recentemente alguns trabalhos apontaram na direção da possibilidade de a mudança ser, às vezes, fonética e lexicalmente gradual, conforme WANG \& LIEN (1993).

LABOV (1981), a propósito da controvérsia envolvendo os dois modelos, evidencia que há muitos casos que dão sustentação ao modelo neogramático. Estes casos mostram que todas as palavras de uma classe são afetadas por uma dada regra. Por outro lado, nem todas as mudanças sonoras seguem princípios neogramáticos. Neste trabalho, Labov argumenta que devemos colocar a regularidade dos neogramáticos nas regras "low-level" e a difusão lexical na redistribuição de uma classe abstrata de palavra em outras classes abstratas.

LABOV (1994), tomando por base estudos da teoria da Fonologia Lexical, dá um novo enfoque ao problema: 

level")

- regularidade nas mudanças $\longrightarrow$ regras pós-lexicais ("low-

- difusão lexical $\rightarrow$ regras lexicais mais especificações de traços fonéticos dentro das entradas do dicionário.

Nos textos de LABOV (1981 e 1994) o alçamento de vogais ("raising") seria uma regra "low-level" (ajuste fonético) e estaria, então, caracterizado como um processo de mudança regular. Isto não se confirma no caso do alçamento de vogais médias pretônicas na região de Belo Horizonte, segundo estudos descritos em VIEGAS (1987).

Em BORTONI et alii (1991) encontramos uma análise do /e/ pretônico nos moldes neogramáticos acerca do dialeto falado na região de Braślia. Já em BORTONI et alii (1992) encontramos uma análise seguindo o modelo neogramático mas em busca de evidências do modelo de difusão lexical.

Em OLIVEIRA (1991), e aqui vou me deter um pouco mais, há uma discussão teórica sobre o processo de mudança sonora, tomando o estudo do alçamento (VIEGAS (1987)) como base fundamental para suas argumentações. Oliveira propõe que toda mudança sonora se dê por difusão lexical, assim como já o dizia PHILLIPS (1984), e que

As primeiras vítimas de uma mudança sonora da forma $X$ $Y / Z$ são as palavras que apresentam os seguintes traços (não necessariamente nesta ordem):

a-Xocorre em um nome comum.

$b-Z$ oferece um contexto fonético para $Y$.

$c-X$ é parte de uma palavra que ocorre em estilos informais.

(OLIVEIRA, 1991: 104)

Itens como ciroulas, cenoura, cebola e simestre, semana e outros continuam sem explicação em OLIVEIRA (1991) (itens estes citados no seu trabalho como contra-exemplos à regra de alçamento 
proposta por Viegas). Todos estes itens citados por Oliveira são nomes comuns, possíveis em estilo informal e que não possuem contexto para a mudança, no entanto uns alçam e outros não. Parece-me que uma análise histórica daria conta destes itens, como veremos posteriormente. É necessário considerarmos a história das palavras para, então, analisarmos a natureza do resíduo. Assim, tumate $x$ tomada (com ambientes semelhantes) não necessariamente indica que um se submeteu à regra e o outro não. Tumate foi incorporado ao léxico português via inglês e, provavelmente, já veio com a vogal reduzida, diferentemente de tomada.

Também em relação aos nomes comuns (em oposição aos próprios), parece-me que a questão é mais ampla e envolve a "valoração semântico-pragmática" do item. Existe uma questão semântica atuando na seleção do item a ser alçado. Assim itens com um sentido desprestigiado socialmente ou que possuam uma carga depreciativa, zombeteira, ou jocosa tendem a alçar mais facilmente: "o purtuga ali da esquina". Em pares de homônimos o item com sentido menos prestigiado, ou desvalorizado socialmente, é mais facilmente encontrado alçado, nunca o contrário. Como em VIEGAS (1987):

Peru (país) X piru (bicho)

porção (determinada quantidade, usado em bares e restaurantes)

$x$ purção (grande quantidade)

É uma questão que abrange nome próprio x nome comum e vai além. É uma questão da valoração social do item lexical. O nome próprio parece ser, normalmente, item valorizado; já itens que possuem um sentido desprestigiado "assumem" o desprestígio deste sentido e são mais facilmente alçados (pois o alçamento é ligeiramente estigmatizado, segundo VIEGAS [1987]).

É importante, pois, destacar:

(...) que a palavra será sempre o indicador mais sensível de todas as transformações sociais, mesmo daquelas que ape- 
nas despontam, que ainda não tomaram forma, que ainda não abriram caminho para sistemas ideológicos estruturados e bem formados. A palavra constitui o meio no qual se produzem lentas acumulações quantitativas de mudanças que ainda não tiveram tempo de adquirir uma nova qualidade ideológica, que ainda não tiveram tempo de engendrar uma forma ideológica nova e acabada. A palavra é capaz de registrar as fases transitórias mais intimas, mas efêmeras das mudanças sociais. (BAKHTIN, 1986: 41)

A questão do estilo merece ser investigada. De conformidade com ABAURRE-GNERRE (1981: 35-36):

Quanto ao levantamento vocálico, parece ser típico dos estilos coloquiais (no sentido de ser inicialmente implementado nesses estilos)...

Ainda segundo OLIVEIRA (1991: 102) (contestando a questão da freqủência mencionada em VIEGAS [1987]):

Também, alta freqüência de ocorrência não parece ser um fator interessante para selecionar as primeiras vítimas do [alçamento pretônico]. Cebola e cenoura, que têm um $e$ categorial, são muito mais freqüentes que ceroula, que tem um $i$ categorial.

Em VIEGAS (1987) o efeito da freqüência do item atuando é evidente no caso de haver ambientes fonéticos favorecedores: meninge $\mathrm{X}$ minino, com vogal alta acentuada. Os dois fatores conjugados influem enormemente no caso do alçamento.

Viegas não está enfocando, em nenhum momento do estudo do alçamento, a questão da freqüência independentemente dos ambientes favorecedores. Portanto, a comparação de Oliveira entre cenoura, cebola e ciroula não serve de contra-exemplo à influência da freqüência na questão do alçamento, pois estes itens não têm ambientes conside- 
rados favorecedores ao alçamento e, além disso, a questão aí é outra: a história da palavra (como já mencionei e veremos adiante).

Talvez a questão deva ser colocada de outra forma: a baixa freqüência do item o deixa mais resistente à mudança. A contraparte a alta frequiência do item o deixa menos resistente à mudança, independentemente de fatores favorecedores - precisa ser testada.

A questão da freqüência precisa ser melhor trabalhada (freqüência absoluta? freqüência relativa?). Subjacente à quantidade manifesta temos a qualidade. Assim os itens freqüentes em determinados grupos são exatamente aqueles que marcam aqueles grupos em determinado tempo (ou que são, de alguma forma, mais relevantes para aqueles grupos). A frequeência difere do estilo, embora ambos possam estar atuando em uma determinada mudança.

Assim, em determinada situação de conversação entram aspectos do grupo, da situação, aspectos do item lexical e aspectos individuais trazidos das vivências e atuaçð̃es do indivíduo neste e em outros grupos.

OLIVEIRA (1992) é um trabalho dentro do modelo de difusão lexical que concentra-se:

... na questão do condicionamento fonético apregoado pelo modelo NG para, a partir daí, comentar também (a) a questão das exceções e a questão da vulnerabilidade maior ou menor de certos itens léxicos a uma mudança sonora, e (b) a questão da dimensão da variação numa abordagem difusionista. (OLIVEIRA [1992: 33])

Resumindo, podemos dizer que:

$1^{\circ}$ - Qualquer segmento pode ser alterado, i.e., em princípio, todo segmento é instável.

$2^{\circ}$ - $O$ contexto que licencia, ou não, a alteração de um segmento é o item léxico. Na verdade, o que muda é a palavra, e não o segmento (ou parte dela). Assim sendo, a vulnerabilidade maior ou menor de um segmento qual- 
quer decorre da vulnerabilidade maior ou menor do item léxico que o contém.

$3^{\circ}$ - Uma vez alterado um determinado segmento (que funciona como um indicador da alteração do item léxico), ele pode se colocar numa relação harmônica ou desarmônica com os segmentos vizinhos elou com os suprasegmentos. Se a alteração conduzir a uma relação harmônica, as chances de que esta alteração vingue são bem maiores.

(OLIVEIRA [1992: 34-35])

A meu ver a mudança se dá no segmento e na palavra. Assim, a vulnerabilidade maior ou menor de um segmento qualquer decorre da vulnerabilidade maior ou menor do segmento e do item léxico que o contém (não só do item léxico) porque o que muda no item léxico é esse segmento, e não outro qualquer, em determinada direção e não em uma direção qualquer.

Existe um percentual altíssimo de alçamento de e em contextos com vogal alta acentuada e um número pequeno de itens não alçados neste contexto. Temos que observar o contexto e as listas de palavras porque as mesmas palavras, (os tokens) sempre alçados, podem estar influenciando o estabelecimento das regras. Obviamente, não ter usado listas conjugadas com a análise dos ambientes deve ter tendenciado as regras propostas em VIEGAS (1987) mas ambientes favorecedores e desfavorecedores existem e as contradições do tipo ciroulas $x$ cenoura; semana $x$ simestre são, em muitos casos, resolvidas por estudos históricos.

Concordo com OLIVEIRA (1992) que a regra não deva ser variável, já que a variação em termos de um item lexical parece ser mínima. Discordo de OLIVEIRA (1992) quando ele faz a postulação do contexto fonético atuando a posteriori, como um fixador da mudança. Segundo Oliveira, as mudanças que "vingam" seriam estabelecidas por relaçôes harmônicas, que seriam processos fonológicos como a assimilação. Relações desarmônicas, como a dissimilação, não estariam previstas na sua formulação de um modelo de mudança. Mas 
LABOV (1994) mostra-nos que as mudanças por dissimilação são processos também freqüentes. Este é um problema para a sua formulação. Além disso, creio que, de qualquer forma, ele terá que estabelecer contextos favorecedores e desfavorecedores (com ponderação de força de atuação e tudo o mais) já que existem relações harmônicas que podem ser quebradas, sistematicamente, por ambientes desfavorecedores. Fica a questão:

Como (e onde) caberiam estas restriçðes, postuladas detalhadamente, na formulação do modelo difusionista proposto em OLIVEIRA (1992)?

Oliveira parece ter razão quando diz:

A menos que haja alguma razão séria em contrário, sugiro que o comportamento individual seja checado para todos os itens lexicais.

(OLIVEIRA [1992: 40])

E com ele ABAURRE-GNERRE (1981: 35-36):

(...) Parece haver grande variação individual com relação ao levantamento de vogais pretônicas: alguns falantes do dialeto levantam, aparentemente, todos os e's e o's pretônicos, mesmo no estilo formal, enquanto que outros raramente of fazem.

Embora FAGAN (1987) tenha mostrado indivíduos variando a sua pronúncia para um mesmo item, este assunto merece ser pesquisado, já que alguns indivíduos alçam aparentemente mais que outros. Se isto é verdade, por que estes indivíduos agem assim e não outros indivíduos, em situações semelhantes? Quem comanda a mudança?

2. Alguns aspectos merecem ser estudados mais detidamente como o item e sua freqüência (as medidas desta freqüência, seu aumento e diminuição, entre outros), os vários sentidos do item, os in- 
divíduos que comandam a mudança, a implementação via estilo, etc. No entanto, nesta seção vou me deter nos itens e sua história.

Faço aqui uma análise inicial de listas de palavras que precisa ser complementada por estudos de textos em, pelo menos, duas épocas distintas e, ainda, por estudos mais específicos dos itens hoje, adotando "o presente para explicar o passado" (LABOV, 1994) como complemento metodológico. Obviamente é um problema inferir formas fonéticas dos registros escritos, mas nossa proposta é fazer "o melhor uso possível de dados ruins". ${ }^{4}$ Estes serão complementados posteriormente por outros estudos.

Pesquisando item por item o Dicionário Etimológico Nova Fronteira da Língua Portuguesa, observei itens com vogal média anterior que, parece-me, são sempre alçados na região de Belo Horizonte e que não têm ambiente favorecedor ao alçamento conforme VIEGAS (1987). Mas observei também que esta lista de palavras é muito pequena, diferentemente do que sugeriu OLIVEIRA (1991), podendo ser arrolada numa lista limitada de itens. Vejamos:
BIZERRO
CIROULAS
MILHOR
SIMESTRE
SINHOR
PIQUENO
TISOURA

\section{LISTA 1}

Se pesquisarmos a evolução destes itens vamos observar que alguns tinham anteriormente i no lugar do e atual. Vejamos:

$$
\begin{aligned}
& \text { BIZERRO }<\text { do lat. hisp. *ibicerra, *ibicírra } \\
& \text { CIROULAS }<\text { do ár. sarāwîl, pl. de sirwâl }
\end{aligned}
$$

Provavelmente estes itens nunca tiveram a pronúncia [e], somente 
conservam o e na escrita. Resta saber por que alguns itens conservam a pronúncia [i], apesar de terem hoje o e na escrita, e outros não.

Ao analisarmos os itens em termos históricos, podemos, talvez, dizer que "ciroulas" tem [i] hoje porque sempre teve a pronúncia i, já 0 item "cenoura" nunca alça porque tem sua origem em:

CENOURA < çanoira < çahanoria (a. cast.) < safunâriya (ár.vulg.).

Assim como:

CEBOLA < do lat. cēpǔlla (dim. de cepa).

Se tentássemos encaixar no modelo neogramático os outroș itens listados, argumenta-ríamos que:

No caso do item MILHOR, com pronúncia sempre alçada nos dados, podemos ter, talvez, uma analogia com pior. Ou uma possível influência do i em měllior-ōris (lat.).

Talvez a analogia fosse também a causa do alçamento em SIMESTRE, comparativa-mente a bimestre e trimestre.

Em SINHOR é possível que tenhamos a influência da vogal alta em SINHOR < sěnǐor-öris (lat.), assim como em TISOURA < tisoyra $<$ do lat. tōnsōría.

Mas e o caso de PIQUENO? Sua origem é imprecisa: $1^{\text {a }}$ datação, séc. XIII. De criação expressiva. Encontrei no dicionário a variação pequeninidade pequininidade no século XV. Talvez esteja na presença destas vogais altas consecutivas a razão para o alçamento do item.

Com relação ao e há um grande número de dados alçados se considerarmos a regra descrita em VIEGAS (1987). Por outro lado, fugindo ao modelo neogramático alguns itens NÃO alçam apesar de terem ambiente para a aplicação da regra. É o caso de meninge, Peru, Sentido!, etc. Parece-me que há aí a questão da frequeência, da formalidade e/ou da valoracão semântico-pragmática do item.

No caso da vogal média posterior temos, formulada em VIEGAS (1987), uma regra muito abrangente e dificilmente encontramos itens 
que nela não se encaixam. Temos porém, muleque e murango. 0 primeiro vem do quimb. mu'leke, ou seja, já possuía, provavelmente, a pronúncia de vogal alta desde a sua incorporação ao léxico português.

Temos, portanto, evidências de que estamos diante de um processo de difusão lexical, pois a regra atinge alguns itens e não atinge outros. Mesmo com todo esforço para encaixarmos todos os itens dentro de uma regra, fica um resíduo, característico do processo de difusão lexical (a seletividade lexical). E é exatamente a natureza deste resíduo que nos interessa analisar. Uma hipótese a ser confirmada é a de que itens como ciroulas tenham tido a pronúncia i desde a sua incorporaçăo ao léxico português. Assim também seria com itens sempre alçados como sinhor, que encontramos registrados com vogal alta há muito no português.

Estes itens que sempre tiveram pronúncia de vogal alta, portanto, devem ser considerados separadamente nos trabalhos que busquem descrever a regra ou o processo de alçamento. Temos que analisar listas de palavras e considerar a origem destas palavras, a época de sua incorporação ao léxico português e sua evolução. Assim também simestre, que pode ser analisado como analogia ${ }^{5}$ a bimestre e trimestre, não pode ser considerado em um conjunto em que se quer apreender o ambiente fonético mais propício ao alçamento.

Podemos arrolar vários itens que, aparentemente, sempre tiveram vogal alta em sua pronúncia, não havendo, pois, o alçamento. É preciso, ainda, "rastrear" a história de cada um. Dentre eles:

$\begin{array}{ll}\text { ALICRIM } & <\text { do ár. al-iklil } \\ \text { ALFURRIA } & <\text { do ár. al-hurrūâa } \\ \text { ALGUDÃO } & <\text { do ár. hisp. al-qutún } \\ \text { ALMUFADA } & <\text { do ár. hisp. al-muhádda } \\ \text { ASSUBIAR } & <\text { séc. XIV, assuuyar (do lat. } \\ \text { BIZERRO } & <\text { adsibilāre) } \\ \text { BUDUM } & <\text { do lat. hisp. *ibicerra, *ibicírra } \\ \text { BULACHA } & <\text { do lat. bulla }\end{array}$


BULINAR

BUNECA

BUNITO

BUTÃO

CIMITÉRIO

CIROULAS

FUGUEIRA

GINGIBRE

GINGIVA

GUVERNO

JATUBÁ

MININO

MISQUINHO

MULAMBO

MULEKE

MUQUECA

MURCEGO

MUSQUITO

MUSTARDA

SUPAPO

TUPETE

TRUVÃO

VILUDO $<\quad$ do fr. bouline

$<\quad$ orig. controvertida, cast. munfeca

$<$ prov. do cast. bueno (>cast. bonito)

$<\quad$ do a. fr. boton, hoje bouton

$<\quad$ séc. XIII, cymiteiro

$<\quad$ do ár. sarāwill, pl. de sirwâl

$<\quad$ séc. XIV, fugueyra

$<\quad$ do lat. zingı̌ber-erris

$<$ do lat. gingiva

$<\quad$ do lat. vulgar gŭuērnāre

< datação 1757, jatubá

< séc. XIII, minino (do cast. mi niño)

$<\quad$ do ár. miskin

$<\quad$ do quimb. mu'lamo

$<\quad$ do quimb. mu'leke

$<\quad$ do quimb. mu'keka

$<\quad$ do a. port. mur (séc. XIII), rato, derivado do lat. mūs mūris, e cego

$<\quad$ do lat. musca

$<\quad$ do lat. medieval mustum,-i

$<\quad$ prov. do fr. soupape

$<$ do fr. toupet

$<\quad$ do lat. vulg. tŭrbo,-ŏnis

$<\quad$ do lat. tard. villūtus

\section{LISTA 2}

Mais uma vez: estes itens devem ser considerados separadamente quando do estabelecimento de uma regra de alçamento, visto que, ao que parece, sempre tiveram a pronúncia [i] ou [u]. Não encontramos estes itens não alçados na amostragem de VIEGAS (1987), mas 
para a possibilidade de uma pronúncia com vogal média HART (1955: 109-110) menciona a "learned reaction":

The simplest explanation would seem to be to admit that $e$ and 0 fell together with $i$ and $u$ in Old Portuguese, and that the distinction has been reintroduced by analogy with other forms of the same word in which the stress shifts from ending to root, as in first singular indicative lego ['LEgu]. But this explanation, which serves well enough for verbs, will not account for the preservation of the distinction in substantives, for here is no shift of accent. One might perhaps see in the distinction between pretonic e and $i$ (and, in Brazil, of o and $u$ as well) a learned reaction, comparable to the adoption in eighteenth-century Spanish of such "spelling pronunciation" as digno, solemne for older dino, solene, or the attempt by some Spanish Americans today to sound the written $p$ for such words as psicologia, septiembre, and to pronounce as $\boldsymbol{k s}$ the written $\boldsymbol{x}$ of texto, exclusivo, which cultivated Castilians pronounce simply as s.

Tudo isto nos leva a crer que, muitas vezes, a vogal média foi introduzida (através de leis ortográficas) na grafia das palavras no português sem, no entanto, estas serem assim pronunciadas.

Por outro lado, como já dissemos, itens que possuíam vogal alta possuem hoje pronúncia de vogal média no dialeto da região de Belo Horizonte. Este é o caso de:

CEGONHA < do lat. cicōnìa

Em alguns casos, os i latinos tornaram-se e no português e são assim pronunciados até hoje no dialeto da região metropolitana de Belo Horizonte (Cegonha, por exemplo). Noutros não, como é o caso de 
Faz-se necessário analisar os contextos (início de palavra $\mathrm{X}$ posição interna à palavra, entre outros) e tentar, então, resgatar a história da mudança.

Existe, ainda, a possibilidade de estar havendo ou ter havido a influência de um processo de rebaixamento de vogais atuando competitivamente à regra de alçamento. Estes estudos precisam ser mais aprofundados e, na impossibilidade de encontrarmos registros dos mesmos itens nas mesmas condições em épocas distintas, devemos fazer como SHEN (1990), que faz uma análise dos itens em diferentes faixas etárias tentando depreender a evolução deles.

Apesar de estes estudos apresentarem mais questóes do que respostas, podemos observar já um fio condutor do processo, ou seja, existe uma regularidade (vogal alta como fator favorecedor, no caso do e), mas também existem algumas palavras que não têm ambiente e possuem a vogal pronunciada [i] ou [u] além do resíduo (palavras que possuem ambiente mas não alçam). Assim, adotamos o modelo teórico da difusão lexical como proposto por WANG \& LIEN (1993), ${ }^{6}$ em que regularidade e processo de difusão lexical não são incompatíveis numa mesma mudança em uma mesma comunidade de fala. $O$ que está em questão não é a regularidade, mas como as exceções são tratadas no modelo neogramático e no modelo difusionista.

Devemos, pois, analisar a natureza do resíduo. Aqueles itens que têm pronúncia de vogal alta e não têm ambiente de aplicação da regra podem em grande parte ser explicados ou por já possuírem vogal alta quando da sua incorporação ao léxico português (ciroulas, etc.) ou por analogia (simestre, etc.). Estas alternativas são previstas no modelo neogramático de mudança sonora regular. No entanto, o resíduo não estaria previsto neste modelo e é este, principalmente, que nos faz optar pelo modelo difusionista. Palavras pouco freqüentes ou mais especializadas como meninge, retina não alçam apesar de terem ambiente para a aplicação da regra. E ainda, nos pares de homônimos o item mais prestigiado socialmente muito freqüentemente não alça 
(Peru x piru) mesmo com ambientes favorecedores. Além destes, podemos notar que os itens quando usados de maneira depreciativa alçam mais facilmente ("o purtuga ali da esquina") e, dependendo do momento da enunciação, itens que normalmente não são alçados podem ocorrer alçados quando se quer dar um sentido zombeteiro, jocoso, etc. (ispirtinho por espertinho).

A palavra parece ser determinante nas situações em que o momento da enunciação tem um apelo mais forte. Em outros momentos, não havendo um apelo maior, a força de atuação estaria no contexto fonético. ${ }^{7}$ Esta é uma hipótese a ser corroborada em estudos posteriores.

3. Pudemos observar alguns pontos que, parece-me, são essenciais:

1) existem ambientes favorecedores às regras de alçamento (vogal alta seguinte, no caso do e) e ambientes desfavorecedores (sílaba CCV, no caso do o);

2) a freqüência, que está de alguma forma ligada ao sentido social do item lexical, influencia no processo de alçamento quando conjugada a ambientes favorecedores;

3) existem itens que resistem a serem sistematizados por regras: murango; Sentido! x sintido; purção x porção.

OLIVEIRA (1994) faz uma análise teórica interessante dos trabalhos recentes acerca da mudança lingüistica e conclui:

a) Continuamos apostando no léxico como controlador das mudanças sonoras, até prova em contrário, e b) entendemos o léxico como um conjunto de traços, ou marcas, construidas nas situações específicas de fala, e não como um conjunto de traços pré-determinados. OLIVEIRA (1994:10-11)

Aqui a questão do estabelecimento dos traços do item (onde e como) merece ser estudada e considerada quando do refinamento do 
modelo teórico.

Concluindo, tomando como concepção de léxico a apresentada em LORD e ZUNG (1992), ou seja, uma estrutura orgânica, plástica, capaz de se acomodar às necessidades dos falantes, optamos por adotar uma concepção de linguagem como enunciação, nas palavras de BAKHTIN (1986:124):

A lingua vive e evolui historicamente na comunicação verbal concreta, não no sistema linghístico abstrato das formas da língua nem no psiquismo individual dos falantes.

Disso decorre que a ordem metodológica para o estudo da língua deve ser o seguinte:

1. As formas e os tipos de interação verbal em ligação com as condições concretas em que se realizam.

2. As formas das distintas enunciações, dos atos de fala isolados, em ligação estreita com a interação de que se constituem os elementos, isto é, as categorias de atos de fala na vida e na criação ideológica que se prestam a uma determinação pela interação verbal.

3. A partir daí, exame das formas da língua na sua interpretação lingüística habitual.

É nessa mesma ordem que se desenvolve a evolução real da língua: as relações sociais evoluem (em função das infraestruturas), depois a comunicação e a interação verbais evoluem no quadro das relações sociais, as formas dos atos de fala evoluem em conseqüência da interação verbal, e o processo de evolução reflete-se, enfim, na mudança das formas da língua.

De tudo o que dissemos, decorre que o problema das formas da enunciação considerada como um todo adquire uma enorme importância.

Assim o homem e sua palavra são autores e criações de seu próprio mundo. Mundo este que contém a palavra concretamente reali- 
zada e o sistema da língua em constante interação.

Pode parecer inusitada a citação de BAKHTIN quando estamos tratando da mudança lingüística (já que este autor é normalmente citado em textos de análise do discurso), mas nossa proposta é justamente tentar mostrar que estes estudos não estão ou não deveriam estar tão distantes assim.

\section{NOTAS}

1

Dentre suas conclusðes gerais seleciono:

- Os fatores que exercem um papel importante na regra podem ser classificados na seguinte hierarquia descendente: a vogal alta da sílaba seguinte, o caráter da vogal átona candidata à regra $\mathrm{e}$ a consoante vizinha.

- Certos fatores tendem a desempenhar o papel de impedir o funcionamento da regra. Desses os mais notáveis são: a palatal precedente, cuja função dissimuladora é clamante na regra do o; a alveolar precedente ou seguinte por razões fonéticas de ordem articulatória e acústica; e o acento subjacente da vogal candidata à aplicação da regra.

- Entre os elementos que tendem a desempenhar o papel de bloquear o funcionamento da regra notam-se especificamente os formadores de grau e outros sufixos que, como esses, propendem para ressaltar o conteúdo significativo da forma base. (BISOL (1981: 260))

2

Tabela dos resultados obtidos na investigação do levantamento pretônico, por PASSOS, PASSOS \& ARAÚJO (1980):

Tabela VII

\begin{tabular}{|c|c|c|c|c|}
\hline $\begin{array}{c}\text { Estrutura } \\
\text { da sílaba }\end{array}$ & Mais Rápido & Menos Rápido & Texto & Palavras \\
\hline CVC & $89,4 \%$ & $80 \%$ & $44,8 \%$ & $5 \%$ \\
CV & $81,3 \%$ & $45,1 \%$ & $29,4 \%$ & $4 \% \%$ \\
VC & $86,1 \%$ & $100 \%$ & $48,8 \%$ & $3,8 \%$ \\
V & $80 \%$ & $66,6 \%$ & $83,3 \%$ & $16,6 \%$ \\
\hline
\end{tabular}


3

$$
\text { (o) } \longrightarrow<\mathrm{u}>/ \mathrm{C}-\mathrm{C}_{0}{ }^{1} \mathrm{~S}
$$

$<$-alternante $><+$ obstruinte $<+$ fricativa $>$

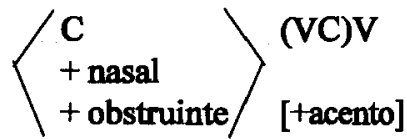

(12)

$$
(\mathrm{e}) \longrightarrow<\mathrm{i}\rangle\left\langle\begin{array}{l}
\neq \neq \\
\neq \neq \mathrm{c}
\end{array}\right\rangle\left[\begin{array}{c}
\mathrm{C} S \\
+ \text { fricativa } \\
+ \text { surda }
\end{array}\right]<\begin{gathered}
\mathrm{C}_{1}{ }^{1} \\
<+ \text { sonorante }\rangle
\end{gathered}\left[\begin{array}{c}
\mathrm{V} \\
+ \text { alta } \\
+ \text { acento }
\end{array}\right\rangle
$$

4

Não encontrei evidências de que os i's e u's tenham sido rebaixados e depois alçados novamente. Estas pesquisas precisam ser confirmadas estudando-se mais detalhadamente a evolução de cada item.

5

"...there is no conflict between LD and analogy: that is, sound change can diffuse 6 through a lexicon by way of analogy." (WANG e LIEN (1993:355))

'NH and LD do not differ in the regularity of language. They are both for the setting up of constraints on linguistic phenomena. Where they differ is in the way in which the exceptions are treated." (WANG e LIEN (1993:348)). 7

É necessário reafirmarmos que os pares de homônimos se distinguem da seguinte forma: se são itens vulgares, chulos (palavrões), jocosos, depreciativos, zombeteiros, menos prestigiados, alçam mais facilmente; se mais valorizados, prestigiados tendem a não alçar. Se a distinção entre os homônimos ocorre para se evitarem os malentendidos (como nos diz LABOV (1994)), por que não temos o contrário: itens alçando mais facilmente se o seu sentido for prestigiado e viceversa? Isto nos leva a considerar o lugar do funcionalismo e do mecanicismo. Estudos estes que devem vir posteriormente.

\section{REFERÊNCIAS BIBLIOGRÁFICAS}

ABAURRE-GNERRE, Maria Bernadete M.: (1981), "Processos fonológicos segmentais como índices de padrões diversos nos estilos formal e casual do Português do Brasil", in: Cadernos de Estudos Lingǘísticos, Campinas, Universidade Estadual de Campinas, n.2, p.23-45.

BAKHTIN, Mikhail (VOLOCHINOV): (1986), Marrismo e Filosofia da Linguagem, $3^{\text {a }}$ ed., São Paulo, HUCITEC (tradução de Michel Lahud e Yara Frateschi Vieira).

BISOL, Leda: (1981), Harmonizạ̧̃o vocálica, Rio de Janeiro, Dissertação de Doutoramento. 
BLUTEAU, D. Rafael de: (1712-1721), Vocabulario Portuguez e Latino, Coimbra, Collegio das Artes da Cia de Jesu (8 volumes, 2 tomos cada).

BORTONI et alii: (1991), "Um estudo preliminar do /e/ pretônico", in: Cadernos de Estudos Linguííticos, Campinas, UNICAMP, n.20.

. (1992), "A variação das vogais médias pretônicas no português de Brasília: um fenômeno neogramático ou de difusão lexical?", in: Revista de Estudos da Linguagem, Belo Horizonte, FALE/UFMG, ano 1, n.1.

CHAUÍ, M.: (1980), O que é Ideologia, São Paulo, Brasiliense.

CHEN, M. \& H-I HSIEH: (1971), "The time variable in phonological change", in: Journal of Linguistic, v.7, Number 1, p.1-13.

CHEN, Matthew e WANG, William: (1975), "Sound Change: actuation and implementation", in: Language 51(2): 255-79.

CUNHA, Antônio Geraldo da: (1991), Dicionário Etimológico Nova Fronteira da Língua Portuguesa, Rio de Janeiro, Nova Fronteira.

FAGAN, David S.: (1987), "On Profiles in Lexical Diffusion”, in: La Linguistique, v.23, fasc. 2, p.47-69.

FIDELHOLTZ, J.: (1975), "Word frequency and vowel reduction in English". CLS 11, p.200-213.

HARRIS, John: (1989), "Towards a Lexical Analysis of Sound Change in Progress", in: Journal of Linguistics 25, p.35-56.

HART JR., Thomas R.: (1955), "Notes on Sixteenth-Century Portuguese Pronounciation", in: Word 11: 404-15.

KHRISHNAMURTI, Bh.: (1978), “Areal and Lexical diffusion of sound change: evidence from Dravidian", in: Language 54(1): 1-20.

LABOV, W.: (1972), Sociolinguistic Patterns, Philadelphia, University of Pennsylvania Press.

. (1981), "Resolving the Neogrammarian Controversy", in: Language, 57 p.307-308.

. (1994), Principles of Linguistic Change: internal factors, Oxford, Black Well.

LESLAU, Wolf (1969): "Frequency as determinant of linguistic change in the Ethiopian languages", in: Word 25, p.180-89.

LORD, R. \& C.T. Zung (1992): "How does the lexicon work?", in: Word 43, p.34973.

MALKIEL, Yakov: (1967), "Each word has a history of its own", in: Word 1:2, p.137-149.

MARTINS, E.J.: (1990), Enunciação e Diślogo, Campinas, UNICAMP.

MATTOS E SILVA, Rosa V.: (1991), "Caminhos de mudanças sintático-semânticas no Português Arcaico", in: Cadernos de Estudos Linguíísticos, Campinas, UNICAMP, n.20.

MOLLICA E MATTOS (1992): "Pela conjugação das abordagens variacionista e difusionista", in: Revista de Estudos da Linguagem, FALE/UFMG, Belo 
Horizonte, p.53-64.

OLIVEIRA, Fernão de: (1975 [1536]), A gramática da linguagem portuguesa Introdução, leitura atualizada e notas por Maria Leonar Carvalho Buesco, Lisboa, Imprensa Nacional - Casa da Moeda.

OLIVEIRA, Marco Antônio de: (1991), "The neogrammarian controversy revisited", in: International journal of the sociology of language, Berlin, v.89. . (1992), "Aspectos da difusão lexical", in: Revista de Estudos da Linguagem, FALE/UFMG, Belo Horizonte, p.31-41.

. (1994), "O léxico como controlador das mudanças sonoras", inédito.

PASSOS, Claiz, PASSOS, Maria Emiliana \& ARAÚJO, Sumaia S.: (1980), "Implicaç̋̃es teóricas do levantamento pré-tónico do Português", in: Anais do V Encontro Nacional de Lingüistica, Rio de Janeiro, PUC/RJ, Vol.1, p.23342.

. (1982), "A velocidade como fator de variação linguística", in: Revista Brasileira de Linguística, São Paulo, SBPL - Livraria Duas Cidades, Vol. 6, n.1, p.93-112.

PHILLIPS, Betty: (1980), "Old English an - on: A new appraisal", in: Journal of English Linguisties, 14, 20-23.

. (1984), "Word frequency and the actuation of sound change", in:Language 60 (2), p.320-342.

SHEN, Zhongwei (1990): "Lexical Diffusion: A Populational Perspective and a Numerical Model", in: JCL 18.1, p.159-200.

VIEGAS, Maria do Carmo \& VEADO, Rosa Maria Assis: (1982), "Alçamento de vogais pretônicas", in: VEADO, Rosa e ALVARENGA, Daniel (org.), Ensaios de Linguística, Belo Horizonte, Faculdade de Letras da UFMG, n.7, p.5370.

VIEGAS, Maria do Carmo: (1987), "Alçamento de vogais médias pretônicas: uma abordagem sociolingũística”, Belo Horizonte, UFMG, Dissertação de Mestrado.

WANG, William S.-Y.: (1969), "Competing changes as a cause of residue", in: Language 45(1): 9-24.

WANG, W. (1990): "Theoretical Issues in Studying Chinese Dialects", in:JCLTA, v. XXV, n.1, p.1-34.

WANG, W. S.-Y. e LIEN, C.: (1993), "Bidirectional diffusion in sound change", in: Historical Linguistics: Problems and Perspectives, Londres, Longman.

WEINREICH, Uriel, LABOV, William \& HERZOG: (1968), "Empirical foundations for a theory of language change", in: LEHMANN \& MALKIEL (eds.), Directions for Historical Linguistics, Austin, University of Texas Press.

WILLIAMS, Edwin B.: (1975), Do Latim ao Português; fonologia e morfologia históricas da Língua Portuguesa, $3^{a}$ ed., Rio de Janeiro, Tempo Brasileiro (traduzido por Antônio Houaiss). 